\title{
FOTOGRAFIAS DE PRÉDIOS ESCOLARES: \\ A CONSTRUÇÃO DE OBRAS VISÍVEIS \\ COMO PROPAGANDA DO GOVERNO \\ SIMÕES LOPES, NA CIDADE DE PELOTAS
}

\author{
Maria Augusta Martiarena de Oliveira ${ }^{1}$ \\ Elomar Antonio Callegaro Tambara ${ }^{2}$ \\ Giana Lange do Amaral $^{3}$
}

Resumo: Augusto Simões Lopes foi intendente da cidade de Pelotas, pelo Partido Republicano Rio-Grandense, entre 1924 e 1928. Durante seu governo foi produzido um grande grupo de imagens que tinham como tema a educação, os quais eram apresentados nos Relatórios Intendenciais e publicados na imprensa republicana, especialmente no jornal Diário Popular e no Almanach de Pelotas. A utilização que foi dada a essas fotografias foi inovadora em Pelotas, pois nenhum intendente anterior produziu um conjunto tão significativo de imagens relacionadas a esse tema. As fotografias retratam, em geral, a fachada do edifício escolar, o que demonstra a necessidade política que, segundo Alves, está unida a uma atração do executivo pelo espaço visível como instrumento que permitiria a continuidade de uma carreira política. Para a realização desse trabalho, optou-se por uma aproximação com os teóricos na Nova História, especialmente Jacques Le Goff. Além disso, utilizaram-se autores que trabalham com fotografias em suas pesquisas, como Kossoy e Mirian Leite. Portanto, buscou-se uma base para a realização da análise das imagens. Buscou-se, ainda, contextualizar o momento em que a pesquisa desenvolvida encontra-se inserida, através de autores que realizaram pesquisas sobre o mesmo tema em âmbito nacional e regional.

Palavras-chave: Educação, Fotografia, Primeira República 


\section{Introdução}

Durante o governo de Augusto Simões Lopes, intendente municipal de Pelotas pelo Partido Republicano Rio-Grandense entre 1924 e 1928, foi produzido um conjunto de imagens de prédios escolares. Percebeu-se que a propaganda foi um dos marcos principais dessa gestão, centrada principalmente no ensino primário e que o grupo de fotografias que envolviam temas referentes a esse era uma característica bastante inovadora entre os governantes municipais.

Como fontes utilizadas para a confecção dessa pesquisa encontram-se as fotografias de prédios escolares apresentadas nos Relatórios Intendenciais de 1926, 1927 e 1928. Foram utilizados, também, os textos fornecidos nos próprios relatórios, o Almanach de Pelotas e o jornal Diário Popular, órgão oficial do Partido Republicano Rio-Grandense. Os referidos relatórios eram produzidos anualmente, notadamente no mês de setembro e apresentavam as realizações do governo municipal.

Levando-se em consideração que o governo Simões Lopes publicou um número considerável de fotografias com a temática de prédios escolares, optou-se por analisar as imagens desse período. Inicialmente, abordaremos as imagens de escolas rurais, que estão em maior grupo, e por fim, as fotografias de grupos escolares.

\section{As fotografias de escolas rurais}

Esse constitui o maior grupo de fotografias produzido para o governo Simões Lopes, até porque, em se tratando de patrimônio construído, foi nesse campo que o ensino municipal teve maior crescimento nessa época. A maior parte das imagens foi publicada no jornal Diário Popular e no periódico Almanach de Pelotas. Os relatórios intendenciais apresentaram dezessete fotografias de escolas rurais, distribuídas da seguinte forma: quatro no relatório de 1926 (15. Escola Isolada, no Cerrito, Escola "Barões de Santa Tecla", no Capão do

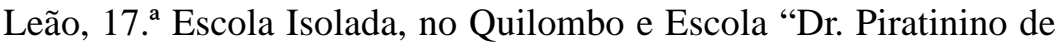
Almeida”, no Areal), uma no relatório de 1927 (Escola Mauá - no 
Passo dos Negros) e doze no relatório de 1928 (Escola Alvaro Berchon, Escola Raphael Brusque, Escola Barão do Arroio Grande, Escola Ministro Fernando Osório, Escola Bibiano de Almeida, Escola Bernardo Taveira Jr., Escola João da Silva Silveira, Escola D. Maria Antonia, Escola Subvencionada do Retiro, Escola Dirceu Moreira, Escola Jacob Brod e Escola Garibaldi).

Durante o governo Simões Lopes, as escolas elementares foram divididas em três graus: o básico, o médio e o integral. O primeiro fornecido nas aulas isoladas, na cidade e na campanha; o segundo nas Escolas Dr. Piratinino de Almeida e Barões de Santa Tecla e o terceiro nos dois grupos escolares urbanos, Dr. Joaquim Assumpção e D. Antonia. Essa medida deixa claro que, além da diferenciação entre as escolas rurais e os grupos escolares, existe, ainda, uma diferenciação entre escolas isoladas (a maior parte delas rurais, criadas na gestão Simões Lopes) e duas outras escolas construídas em zonas periféricas, mas que podiam oferecer mais séries do que as incluídas no grau básico. Então, ao trabalhar com esse grupo de fotografias, deve-se ter em conta que as escolas não constituíam um grupo homogêneo.

A própria ordem em que as escolas aparecem no decorrer dos relatórios intendenciais, especialmente no relatório de 1928, aponta para a hierarquia prevista na medida acima mencionada, que, em uma escala decrescente, inicia-se pelos grupos escolares, passando pelas escolas rurais e chegando até as aulas subvencionadas.

Quanto aos prédios, nem todos foram construídos especialmente para serem escolas, vários deles foram adaptados para essa função, conforme pode ser percebido em diversas matérias do jornal Diário Popular, quando da inauguração das escolas, notadamente das primeiras. Alguns dos prédios adaptados possuem uma área maior do que os construídos, que seguiram o modelo do grupo escolar do "typo" rural ${ }^{4}$. Entre os prédios adaptados estão as Escolas Dr. Piratinino de Almeida e Barões de Santa Tecla.

As fotografias, em geral, são tiradas de um ângulo que permite a visualização, além da fachada, da parte lateral do prédio. No conjunto estudado, quase todas as fotos mostram os prédios. São poucas as fotografias de escolas feitas quando da inauguração das mesmas, como é o caso da fotografia da escola Álvaro Berchon (figura 1). 
Segundo Borges (2003), muitas vezes, enquanto os códigos culturais do fotógrafo definem a composição dos cenários fotográficos, a velocidade da câmera pode captar fragmentos do real, não previstos na idealização das poses, porque a chapa fotossensível capta a luz emanada do objeto fotografado, sem a intervenção humana. Roland Barthes afirmou que a fotografia, nessa e apenas nessa fração de tempo, é uma mensagem sem código. "Os planos, os focos, o jogo de sombra e luz que a compõe são marcados pela encenação que a intenção do fotógrafo cria. O produto fotográfico oscila "entre aquilo que escapa e isto que nela infiltra”. (BORGES, 2003, p.84).

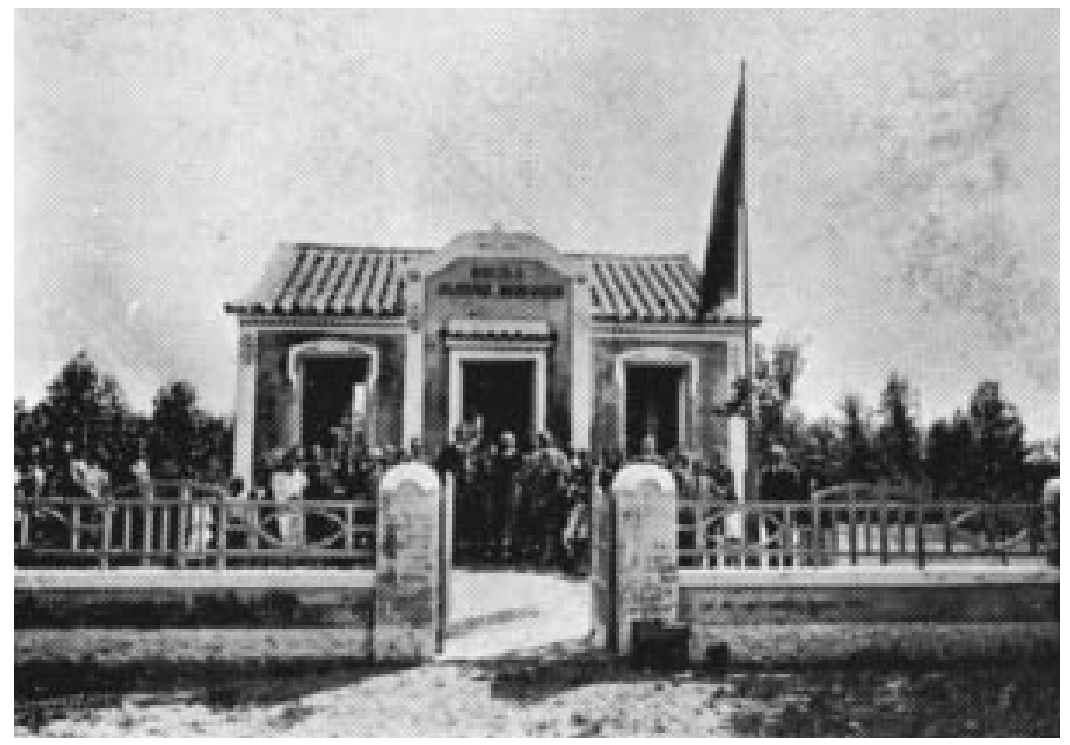

Figura 1 - Escola Álvaro BerchonFonte: Relatório Intendencial de 1928

Percebe-se que as fotografias de escolas (isso inclui as duas fotografias dos grupos escolares) devem ter sido feitas com o intuito de mostrar as condições arquitetônicas das escolas e o seu entorno. Nesse período, houve uma preocupação muito grande com a arquitetura escolar e com as condições de higiene e ensino das escolas. De acordo com Escolano (2000), a arquitetura escolar é por si mesma um programa, uma espécie de discurso que institui em sua materialidade 
um sistema de valores, como os de ordem, disciplina e racionalidade, que são marcos para a aprendizagem sensorial e motora. Consiste, também, em toda uma semiologia que cobre diferentes símbolos estéticos, culturais e ideológicos. Ao mesmo tempo, o espaço educativo refletiu em seu formato as inovações pedagógicas, tanto em suas concepções gerais quanto em seus aspectos mais técnicos.

Para esse autor, os espaços educativos estão dotados de significações e transmitem uma importante quantidade de estímulos, conteúdos e valores, impondo, ao mesmo tempo, suas leis como organizações disciplinares. Não somente o "espaço-escola", mas também a sua localização, a sua disposição na trama urbanística, deve ser analisada como um elemento curricular. Dependendo de onde estiver localizada a escola, ela poderá ser considerada como o centro de um urbanismo racionalmente planificado (Grupo Escolar Dr. Joaquim Assumpção) ou como uma instituição marginal.

A criação de escolas municipais, ocorridas nesse momento, se contrapõe à existência de escolas isoladas. Conforme Faria Filho (1996), até o início do século XX, o processo de criação e estabelecimento de uma escola isolada de instrução pública era bastante simples. Bastava que um professor ou professora, titulado ou não, ou um grupo de moradores de determinada localidade, procedendo ao levantamento do número de crianças em idade escolar residentes na região, e verificando número suficiente de meninos e meninas, solicitasse a criação de uma cadeira de instrução primária local. Muitas vezes, a efetiva criação da cadeira dependia tanto do interesse das autoridades estaduais em prestigiar uma dada região ou pessoa, quanto da pressão exercida pelos interessados, principalmente pelas famílias.

Segundo ele, a escola isolada era apresentada como aquela que funcionava nas casas dos professores ou em outros ambientes pouco adaptados ao funcionamento de uma escola pública de qualidade, como sendo um obstáculo quase intransponível à realização da tarefa educadora e salvacionista republicana, materializada na educação primária. Em Pelotas, apontou-se, assim como em outros lugares do país, para a necessidade de criar um local adequado para o ensino, apresentando-se o ideal republicano para a educação. Augusto Simões Lopes demonstrou o seu interesse por esse setor já em seu discurso de posse: 
A escola pública precisa ser dotada de casa própria, mobiliário adequado e apparelhada de todo o material necessário. O menino deve instruir-se e educar-se. Deve olhar para a escola como para um symbolo de fé e esperança no porvir nacional, que só pode brotar da consciência esclarecida de cada um de nós. Não descuidarei, portanto, da imprescindível propagação desses centros de cultura intellectual, em cujos benefícios confio inteiramente, esperando merecer do governo do Estado, valioso concurso no que respeita as atribuições que lhe competem (DIÁRIO POPULAR, 2 de setembro de 1924).

Mesmo apontando-se para a necessidade de criar prédios destinados a serem escolas, seguindo as condições adequadas para esse fim, continuaram existindo na cidade as aulas isoladas e o ensino em domicílio, tanto primário quanto secundário. Muitos desses eram considerados impróprios para a prática do ensino e foram intensamente criticados por Augusto Simões Lopes, que afirmou: "A cidade mesmo offerece deploráveis aspectos - grande numero das suas escolas particulares não se recommenda como acceitaveis, pela inadaptação dos prédios em que funccionam", (RELATÓRIO INTENDENCIAL, 1925, p.28).

E é nesse ponto que se pode perceber que a seleção das fotografias das escolas não passou apenas por uma escolha de ângulo. Nem todas as escolas criadas no governo de Augusto Simões Lopes foram representadas em seus relatórios. As fotografias referem-se apenas a escolas municipais, cujos prédios foram adaptados ou construídos.

Segundo Leite, "Convém ainda distinguir, na leitura da fotografia, o que ela reproduz da condição do grupo retratado, o que silencia desse grupo e os indícios que permitem ao observador perceber ou sentir outros níveis da realidade", (Leite, 1993, p.76). Logo, ao utilizarem-se fotografias como fonte de pesquisa, faz-se mister perceber o que está presente no seu conteúdo e o que está ausente. Além da ausência das escolas que não funcionavam em prédio próprio, percebese, também, a ausência de fotografias do interior das escolas, o qual era minuciosamente descrito nos jornais, especialmente no Diário Popular. Essa lacuna pode ser explicada pelo fato das escolas possuírem pequenas instalações que não causariam o mesmo impacto que as suas facha- 
das, representadas de forma a parecerem maiores do que realmente eram. Existe, também, a possibilidade de a técnica de fotografar no interior não ter rendido boas imagens. Ou ainda, porque sendo cara, a fotografia foi restringida à apresentação geral. Ou, também, talvez os prédios não estivessem em tão boas condições como era descrito no Diário Popular. Abaixo, em matéria desse jornal sobre a inauguração da Escola Dr. Piratinino de Almeida, temos a sua descrição:

Em espaçoso prédio, que soffreu as reparações necessárias, ficando em excellentes condições para o mister a que foi destinado. O edifício, um dos maiores do local, tem espaçosas acommodações, jardim com gradil e portão de ferro na frente, tendo sido dotado de installações sanitárias. O mobiliário escolar completo, é todo novo e moderno. (DIÁRIO POPULAR, 5 de maio de 1926).

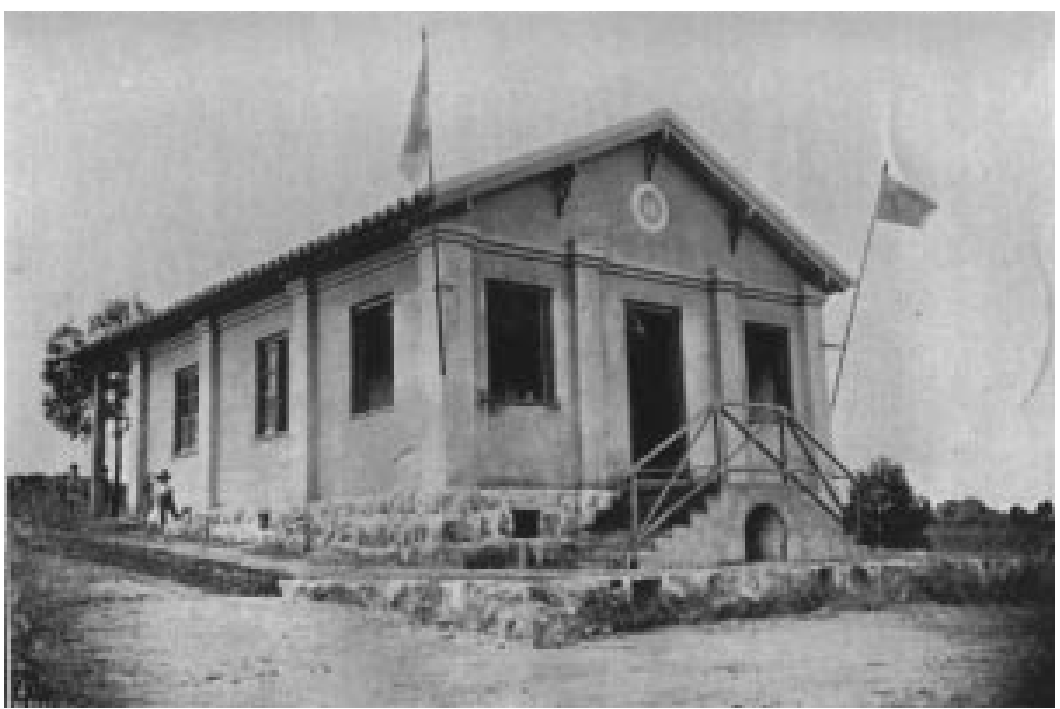

Figura 2 - 17. ${ }^{a}$ Escola Isolada, no Quilombo Fonte: Relatório Intendencial de 1926

Esse tipo de descrição ganha ainda mais vigor, ao tratar-se da 17. A Aula (figura 2), na Represa do Quilombo, que foi “o primeiro 
edifficio que o nosso amigo dr. Augusto Simões Lopes mandou construir para servir á instrucção primaria na campanha, e que tanto desvello lhe tem despertado". (DIÁRIO POPULAR, 30 de maio de 1926):

As dependências do prédio constam de sala para aula, trés quartos, sala para refeições, cosinha e alpendre, tendo sido abastecido de água, obtida por captação especial e de serviço de exgottos, com fossa bacteriológica, para 25 alumnos. A arca coberta abrange a superfície de 82 metros quadrados, approximadamente, De aspecto singelo, mas elegante, foi o prédio construído para os fins em vista.

Retomando a importância de prédios construídos especialmente para tornarem-se escolas, de acordo com Escolano (2000), o edifícioescola é uma variante da chamada arquitetura institucional, mas apresenta, em sendo uma variante, uma determinada força semântica através dos signos e símbolos que exibe. Quanto à escola no meio rural, segundo Escolano (2000), a arquitetura escolar desempenhou uma função educadora inequívoca, especialmente nesse meio, pois existia um prestígio maior atribuído aos professores, e sua profissão estava associada ao prestígio do lugar onde aconteciam as aulas. Além disso, deve-se ter em conta que a escola serviu, como afirma Escolano (2000), de estrutura material para colocar, entre outras coisas, o escudo pátrio, a bandeira nacional, símbolo presente em várias das fotografias de escola do governo Simões Lopes.

Provavelmente, a característica de evidenciar aspectos da sua localização, comum na maior parte das escolas, aponte para essa questão (localização das escolas), que foi amplamente discutida na década de 1920. De acordo com Frago (2001), os critérios básicos que condicionam a eleição da localização são de ordem higiênica e moral. Sobre a higiene, esse autor nos aponta que era considerado como ideal um local elevado, seco, bem arejado e com sol, evitando-se os lugares úmidos, sombrios e não arejados.

Através de uma fotografia da época e das condições em que elas ainda eram produzidas (preto-e-branco), torna-se difícil perceber a presença de alguns desses detalhes, como se o local era ensolarado, ou úmido. Porém, quanto à localização, as fotografias da 17. ${ }^{a}$ Escola Isolada do Quilombo (figura 2) e da Escola Mauá (figura 3) denotam 
que as escolas encontravam-se situadas em locais elevados, como era prescrito. Na primeira, por exemplo, o fato de a fotografia ter sido tirada de baixo para cima, causa a impressão no seu observador de que a escola encontra-se em patamar mais elevado do que o entorno que a rodeia. A primeira escola construída por Augusto Simões Lopes, com seus dois mastros laterais, servindo orgulhosamente de sustentação para duas bandeiras, parece apontar para o céu, para o lugar elevado que a educação almejava atingir na cidade de Pelotas, de acordo com o discurso construído por Augusto Simões Lopes. Já a segunda, pela distância e ângulo no qual a escola foi retratada, conduz à idéia de que, também ela, esteja situada em posição mais elevada do que o local que a cerca. Após uma observação maior, perde-se esta impressão, percebendo que a escola está no mesmo patamar do seu entorno, sendo elevada apenas pela presença de um porão (presente também na escola anterior), que prescindiu a presença de uma escada.

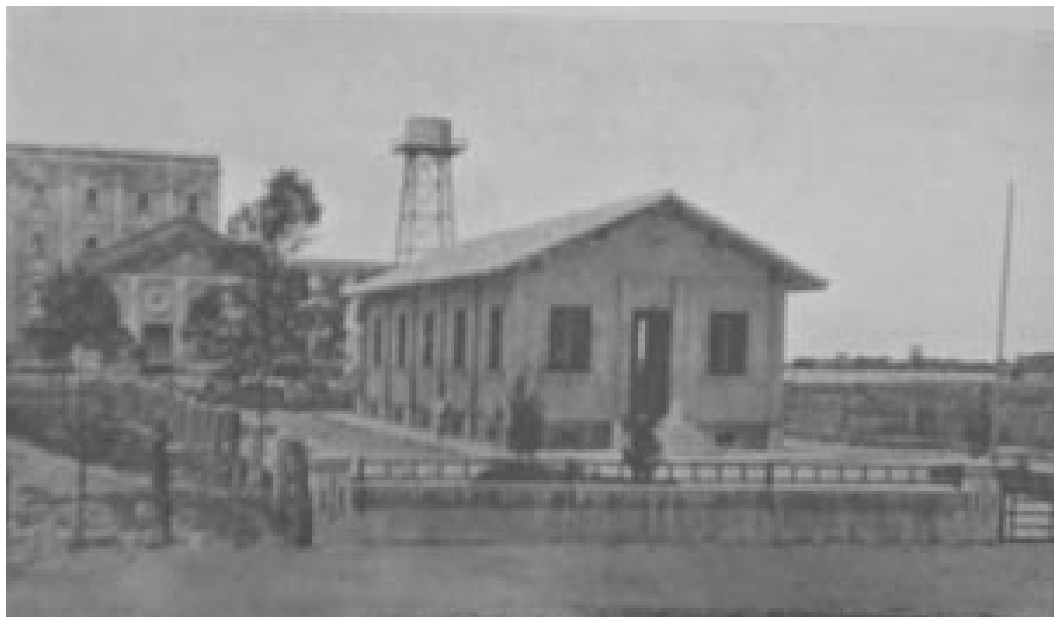

Figura 3 - Escola Mauá

Fonte: Relatório Intendencial de 1927

Retomando novamente a $17 .^{\text {a }}$ Escola Isolada do Quilombo, a sua localização, extremamente valorizada na sua respectiva fotografia, foi também exaltada quando da sua inauguração, em matéria do jornal Diário Popular: 
A margem esquerda do arroio Quilombo, em ponto elevado, com lindo panorama denominado a represa do Quilombo, um dos municipaes que abastecem a cidade, foi pelo nosso distincto amigo dr. Augusto Simões Lopes, operoso intendente, resolvida a construcção do edifício não só para a moradia do respectivo guarda como destinada também á sede de mais uma escola, de longa data reclamada pelos moradores do local, (DIÁRIO POPULAR, 30 de maio de 1926).

Além da localização, uma característica marcante nesse grupo de imagens é a uniformidade de suas construções, principalmente daquelas que foram baseadas no modelo do grupo escolar do "typo" rural, como a Escolas Álvaro Berchon (figura 1). Algumas delas apresentam uma arquitetura mais despojada, beirando o estilo colonial, enquanto outras apresentam uma arquitetura aproximada do estilo eclético, que foi característica dos grupos escolares em Pelotas.

Mesmo com pequenas diferenças, a uniformidade prevalece. Além disso, a uniformidade dos prédios é o corolário da uniformidade pretendida para os currículos. De acordo com Nunes (1993), as instalações pedagógicas teriam por objetivo fazer resultar da sua uniformidade a uniformidade dos processos pedagógicos em todas as escolas primárias. Para essa autora, a escola ideal nada mais é do que um ponto de referência pelo qual os problemas da escola real nas áreas suburbana e rural são detectados e solucionados a priori. Mais do que um modelo propriamente dito, é um módulo que se codifica pelo acréscimo de outros, mas que não muda a sua substância: exercer uma ação pedagógica (higiênica) sobre alunos e professores, que se irradiasse para o ambiente familiar.

Passa-se, agora, a abordar as imagens dos grupos escolares, ou seja, das escolas urbanas construídas durante o governo de Augusto Simões Lopes.

\section{Os Grupos Escolares: D. Antonia e Dr. Joaquim Assumpção}

Esse grupo contêm apenas três imagens, as quais foram extraídas do relatório de 1927 e divulgadas no Almanach de Pelotas, com a 
mesma legenda - uma delas não se refere à instrução pública e sim a obras de melhoramentos urbanos. Nesse relatório, como mencionado anteriormente, além das duas fotografias dos grupos escolares, existia apenas uma fotografia de escola rural. Isso se deve, provavelmente, à visibilidade e à relevância que a construção/inauguração de dois grupos escolares urbanos trouxe para as políticas educacionais do governo.

De acordo com Souza (2004), em meados do século XX, os grupos escolares se haviam tornado a modalidade de escola primária predominante no país, acompanhando o processo de urbanização e democratização do ensino público. Embora não se possa menosprezar a participação de outros tipos de escolas primárias, visto que, notadamente, as escolas isoladas foram responsáveis pela escolarização de um grande contingente da população brasileira.

Tanto a escola D. Antonia (figuras 5 e 6 ), como a Dr. Joaquim Assumpção (figura 4), foram construídas para serem os grupos escolares modelos da cidade de Pelotas. A propaganda quando do surgimento da idéia da construção foi muito grande em relação a ambas. Porém, com o tempo, o último grupo acabou por ganhar muito mais visibilidade e solidificou-se como a principal escola municipal construída no governo Simões Lopes, sobre a qual recaíam todas as propagandas. Como exemplo disso, pode-se citar a matéria do jornal Diário Popular de 10 de agosto de 1927:

Ainda ha pouco, de passagem por Pelotas, e visitando aquelle Grupo, em companhia do nosso illustre amigo dr. Augusto Simões Lopes, operoso intendente e benemerito reorganizador da instrucção, o sr. dr. Faria Netto, alto funccionario do ensino publico em São Paulo, em excursão de estudo pelo nosso Rio Grande, teceu francos elogios áquelle edifício e ás suas excellentes condições de hygiene, que disse não existirem melhores no seu Estado, mostrandose até admirado que o Município, dentro de suas forças orçamentárias levasse a cabo obra de tal magnitude.

Cabe observar, ainda, antes mesmo de analisar a própria imagem, o local que ela ocupa dentro do impresso em que está inserida. De acordo com Leite (1993), a leitura das fotografias exige sempre a 
formação de sequências para completar sua mensagem e de uma hierarquização que permita penetrar as relações internas das posições sociais ou uma ordenação cronológica expressiva. $\mathrm{O}$ trabalho com impressos, dessa forma, facilita a percepção de uma hierarquização que já está presente no ordenamento em que a imagem aparece, seja no relatório, no Almanach ou no jornal.

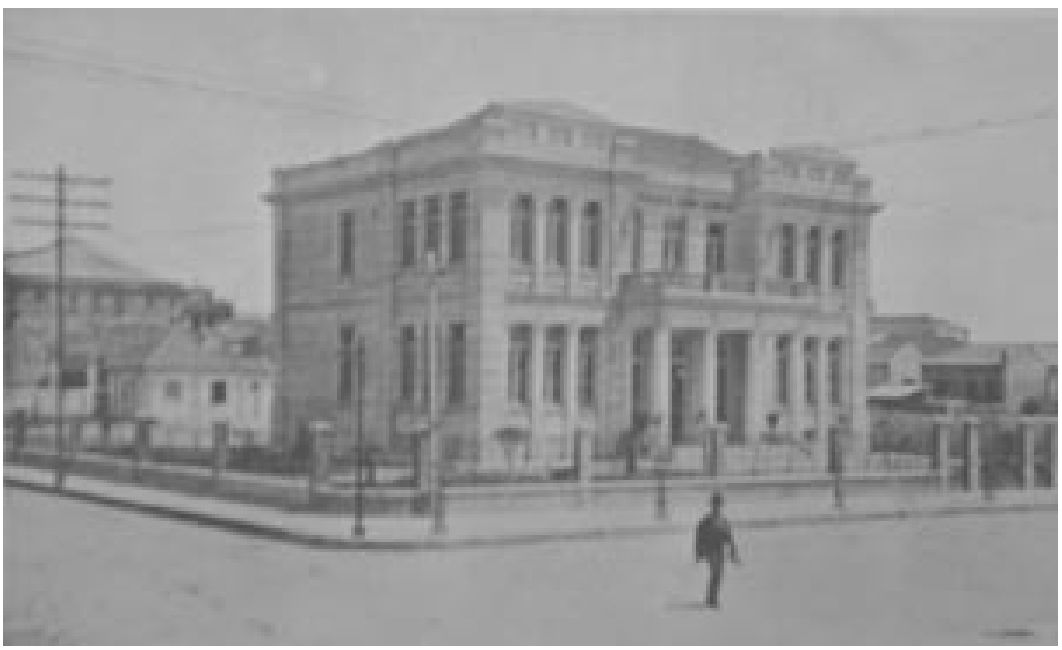

Figura 4 - Grupo Escolar Dr. Joaquim Assumpção Fonte: Relatório Intendencial de 1927

No relatório de 1927, a fotografia do Grupo Escolar Dr. Joaquim Assumpção (figura 4) foi a primeira imagem referente à educação ali apresentada, seguida da fotografia do Grupo Escolar D. Antonia (figura 5) e, por fim, de uma das escolas rurais. O que pode ser uma simples coincidência, também pode representar a definição de uma ordem de importância, do lugar que cada instituição ocupa na política da instrução pública de Augusto Simões Lopes, partindo do estabelecimento que se encontra em primeiro lugar (o maior e mais importante), passando para o que se encontra na segunda posição (apesar de ser um grupo escolar, o D. Antonia não possui a mesma grandiosidade, especialmente no que tange as suas dimensões), para chegar aquele que ocupa o último lugar em importância, uma escola rural. A baixo das escolas 
rurais, encontravam-se as aulas subvencionadas, porém, ao contrário do relatório de 1928, que apresenta diversas fotografias de escolas rurais, o de 1927 só apresenta essa, que, comparativamente às outras, especialmente a primeira, ocupa um patamar inferior. Mesmo no relatório de 1926, o desenho da fachada do Grupo Escolar Dr. Joaquim Assumpção foi apresentado antes da fachada do D. Antonia, antecedendo, ainda, as quatro fotografias de escolas rurais.

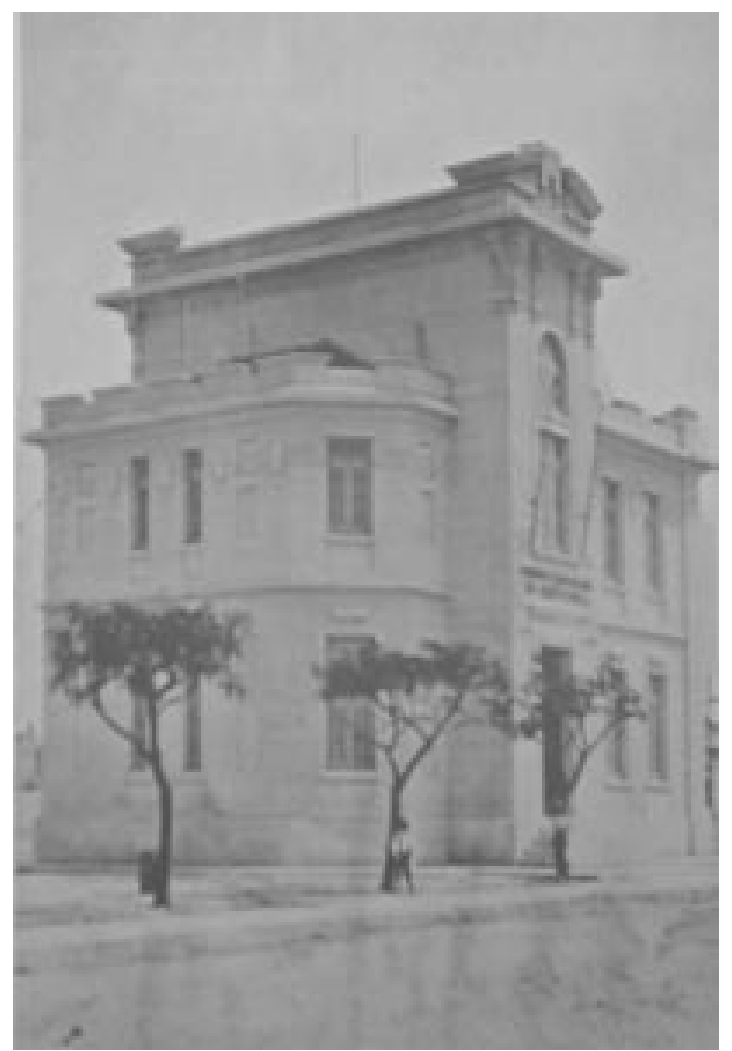

Figura 5 - Grupo Escolar D. Antonia

Fonte: Relatório Intendencial de 1927

Em matéria do jornal Diário Popular de 1. e setembro de 1928, a fotografia do Grupo Escolar Dr. Joaquim Assumpção ocupa o lugar 
central da segunda página, assim como na primeira, a fotografia do próprio intendente. A segunda página, cujo centro foi destinado à fotografia do Grupo Escolar Dr. Joaquim Assumpção, rodeada de imagens de outras escolas, as quais já foram citadas anteriormente, aponta para a idéia de que o referido Grupo Escolar ocupava, também, o lugar principal entre as obras da instrução pública do governo Simões Lopes. Essa instituição, ali representada em posição central, estava sendo considerada como o estabelecimento de ensino primário mais importante de Pelotas. Para completar os estudos primários, os estudantes das outras escolas (com exceção do D. Antonia) deveriam dirigir-se a ela, onde receberiam o ensino integral de cinco anos, ou seja, o impresso reflete as categorias de escolas.

Depois de perceber-se a relação da localização da imagem nos impressos, com a relevância que cada instituição escolar possuía, tornase interessante observar a própria fotografia. Visto que se verificou um ordenamento, optou-se por começar pela fotografia do Grupo Escolar Dr. Joaquim Assumpção (figura 4). Assim como as das escolas rurais, essa fotografia também foi tirada de um ângulo que torna possível visualizar a fachada e a lateral do edifício, mostrando a inteireza de sua monumentalidade.

Além disso, assim como as outras imagens de escolas, a intenção principal é mostrar a arquitetura escolar e a sua localização. Não se conta com a presença de alunos, apenas de um pedestre que, atravessando a rua, serve como referencial para evidenciar o tamanho do prédio. Além do pedestre, também os prédios do entorno subjugam-se ao tamanho do Grupo Escolar, que se destaca pela sua imponência. Conforme Escolano (2000): "la escuela debería ser el elemento dominante del conjunto de construcciones que la rodean, siendo el símbolo que represente el esfuerzo en favor de la cultura". (ESCOLANO, 2000, p.190).

O Grupo Escolar D. Antonia, assim como o Dr. Joaquim Assumpção, também possui em sua fotografia informações que permitem a identificação da localização da escola como sendo no perímetro urbano. Isso pode ser percebido, especialmente, pelo calçamento da rua e pela disposição de como as árvores foram plantadas. Ao contrário da fotografia anteriormente citada, não existiu intenção de retratar os prédios do entorno da escola da forma como foi ali foi feito. Localizados sutilmente ao 
fundo da imagem, eles são quase imperceptíveis, e a pequena parte visível na imagem, propicia a impressão de que o Grupo Escolar D. Antonia era bastante grande. Além disso, os principais referenciais utilizados para possibilitar a compreensão das dimensões da escola são uma criança e as árvores. Por detrás desses elementos, o Grupo Escolar D. Antonia impõe a sua grandiosidade. Essa forma de retratar a arquitetura de prédios escolares é muito interessante, especialmente quando o interesse principal é fazer com que determinado prédio pareça maior do que realmente é. A fotografia, dessa forma, aponta para a subjetividade do espectador, pois o espaço delimitado pela fotografia permite jogar com as informações sobre o tamanho dos prédios, conforme os referenciais (criança, árvores, prédios) que utiliza.

A terceira fotografia desse grupo (figura 6), como já foi dito, não se refere à instrução pública municipal, mas é uma vista da Avenida Saldanha Marinho, que parece objetivar tornar notório o seu recente ajardinamento. Tanto nos jornais quanto nos relatórios, essa avenida onde foi construído o Grupo Escolar D. Antonia é apresentada como "futurosa" e é justamente essa imagem que foi transmitida através da fotografia. A avenida de duas pistas mostra-se ampla, limpa e moderna. Essa imagem foi tirada de um ângulo levemente oblíquo aos jardins e ao Grupo Escolar, o que acarretou uma certa simetria à imagem, bastante parecida com aquela presente em pinturas barrocas. Pode-se traçar uma linha diagonal que parte da charrete estacionada em frente ao jardim até o D. Antonia. Dividindo-se a fotografia em duas partes, percebe-se que a charrete ocupa o centro do lado esquerdo do observador, enquanto o D. Antonia é o centro do lado direito.

Essa escola surge, em meio ao recente ajardinamento apontado pela legenda, como um gigante em meio a poucos ou distantes prédios, fazendo com que a pequena escola ganhe uma aparência monumental. As fotografias que retratam essa escola estão marcadas pela presença de referenciais que fazem com que o observador tenha a impressão de que o prédio da escola é muito maior do que realmente é. Nessa imagem, especificamente, o tamanho das árvores, as indústrias ao longe, as charretes, ou seja, o entorno do Grupo Escolar D. Antonia, da forma como foi retratado, causa a impressão de que o referido prédio possui dimensões grandiosas. 


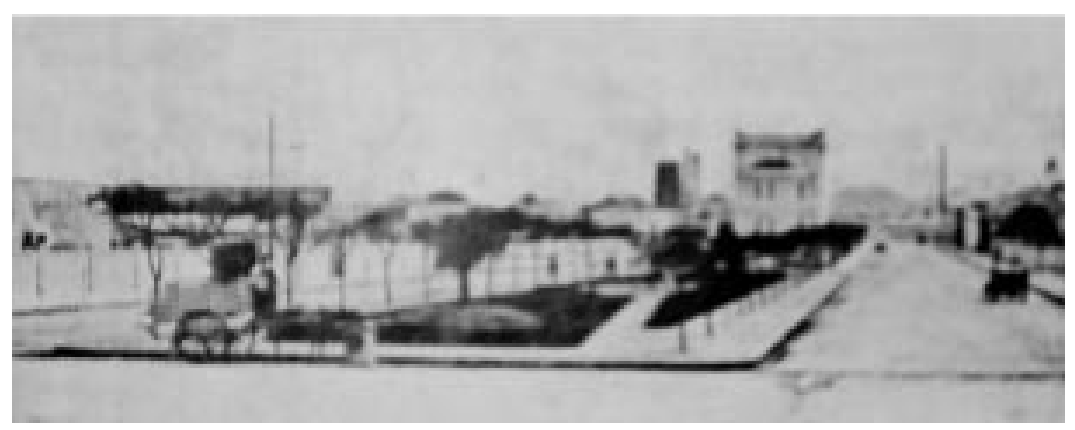

Figura 6 - Avenida Saldanha Marinho com seu recente ajardinamento Fonte: Relatório Intendencial de 1927

Essa fotografia permite, também, perceber o lugar que o Grupo Escolar passou a ocupar na trama urbanística, tornando-se um signo de modernidade e progresso. No fundo da imagem pode-se perceber que, ao longe, delineiam-se formas que parecem definir a presença de indústrias nas proximidades da escola. O Grupo Escolar, portanto, insere-se em uma sociedade que pretendia alcançar o desenvolvimento econômico e intelectual. Mesmo que a imagem pareça ter como objetivo mostrar o ajardinamento do canteiro central da Avenida Saldanha Marinho, pode-se observar que o fotógrafo não deixou de valorizar o D. Antonia, colocando-o em uma posição de destaque na imagem. Reafirma-se, então, o caráter de modernidade que a fotografia pretende transmitir por meio de vários elementos constantes na imagem: o jardim, a ampla avenida e o Grupo Escolar.

Além das informações referentes às dimensões dos prédios, as fotografias desse conjunto permitem, também, a percepção de determinadas características compreendidas pelos grupos escolares. De acordo com Buffa (2002), os terrenos selecionados para abrigarem os grupos escolares eram, em geral, quadras inteiras ou grandes lotes de esquina. Além disso, segundo essa autora, os grupos escolares possuíam algumas determinadas características, tais como: fachada grandiosa, hall de entrada primoroso, escadarias, duas alas, eixo simétrico, pátio interno, acabamento com materiais nobres, portas com bandeiras, janelas verticais grandes e pesadas, carteira para dois alunos, relógio redondo com algarismos romanos, etc. 
Várias dessas características deixam-se vislumbrar através das imagens que mostram a parte exterior do prédio. Logo, apenas aquelas que se referem ao exterior (fachada grandiosa, escadarias, grandes janelas verticais). Além disso, como pode ser observado, o Grupo Escolar Dr. Joaquim Assumpção foi construído em um grande lote de esquina e, o Grupo Escolar D. Antonia, no canteiro central da Avenida Saldanha Marinho, ambos ocupando uma posição de destaque onde estavam situados.

Além dessas características, Buffa (2002) afirma que a arquitetura dos grupos, embora não seguisse uma unidade, estava ligada pelo seu academicismo e, em geral, era marcada pelo neoclassicismo que, segundo a autora:

Era uma forma de ecletismo onde é possível encontrar justapostos todos os estilos que utilizam coluna, cornijas e frontões da Renascença Italiana ao Segundo Império Francês, passando pelo classicismo, pelo barroco e pelo verdadeiro neoclássico de fins do século XVIII e primeira metade do XIX, (BUFFA, 2002, p.44).

Percebe-se, também, nos prédios, a presença de dois mastros. Sobre esses, pode-se dizer que a bandeira nacional, símbolo do civismo, esteve presente nas escolas rurais e urbanas, pois, para Souza (1996): "Os republicanos fizeram da educação popular um meio de propaganda dos ideais liberais republicanos e reafirmaram a escola como instituição fundamental para o novo regime e para a reforma da sociedade brasileira", (SOUZA, 1996, p.19).

As fotografias de escolas, especialmente as dos grupos escolares, demonstram uma necessidade política descrita por Alves (1998). Essa autora afirma que: “criar espaço com obras visíveis (inaguráveis, com o capitalismo), faz parte do modus operandi, e constitui um habitus dos ocupantes do núcleo do campo político na sua prática". (ALVES, 1998, p.98). Segundo ela, existe uma atração do executivo pelo espaço visível, que se mostra mesmo para aqueles iniciantes no campo político, visto que a continuidade neste é sempre uma possibilidade. 
De certa forma, a preocupação de Augusto Simões Lopes em construir um conjunto de obras que dessem visibilidade ao seu governo - obras que incluem notadamente aquelas relativas à educação, mas não somente estas, pois no governo de Augusto Simões Lopes planejou-se, também, a construção do Grande Hotel - pode ser explicada pelo interesse deste em seguir a carreira política, o que realmente aconteceu. Augusto Simões Lopes tornou-se Senador na década de 1930. E, no tocante à visibilidade, o intendente não se limitou a construir muitas escolas e dois grupos escolares, ele difundiu a sua imagem na imprensa para que a sua obra fosse amplamente conhecida.

Ainda inserido na questão da visibilidade dos feitos, percebe-se que o Grupo Escolar Dr. Joaquim Assumpção, assim como o "Gymnasio Pelotense", representou a competitividade entre o governo municipal e o estadual. Essa competitividade ficou expressa através de inúmeras matérias sobre o desenvolvimento de Pelotas e sobre como esta cidade deveria ser seguida como modelo para as iniciativas do governo estadual e para outras cidades do estado.

O Grupo Escolar Dr. Joaquim Assumpção, estando vinculado ao governo municipal, ocupou o lugar de antagonista dos Colégios Elementares Félix da Cunha e Cassiano do Nascimento, ambos estaduais. A idéia de que o grupo escolar modelo municipal seria mais moderno, mais preparado, construído para atender a todas as necessidades apontadas pela pedagogia moderna, está presente na imprensa a todo o momento, colocando o ensino municipal como mais bem preparado do que o estadual. O Dr. Joaquim Assumpção teve, então, a responsabilidade de concorrer com os dois colégios elementares já constituídos há mais tempo em Pelotas e com mais de uma década de existência. A escola preconizava o moderno, ao mesmo tempo em que os seus próprios signos de modernidade representavam a manutenção da tradição. Tradição, essa, de Pelotas ser uma cidade de vanguarda.

Nos relatórios não foram apresentadas fotografias internas dos Grupos Escolares, com exceção da fotografia de uma aula de trabalhos manuais, da temática "imagens do cotidiano escolar", apresentada no relatório de 1928, sem definir a escola onde foi tirada (pela 
legenda da imagem no Almanach de Pelotas, descobre-se que se trata do Grupo Escolar Dr. Joaquim Assumpção).

Ambos os grupos escolares foram descritos nos relatórios e no Diário Popular (publicaram-se grandes matérias quando das suas inaugurações, apresentando, inclusive, as plantas dos dois grupos). Sobre o D. Antonia, apontou-se: “[...] abrange uma area de 119 metros quadrados, dispondo de duas aulas, saguão, gabinetes da directoria e medico, com todos os serviços sanitarios" (RELATÓRIO INTENDENCIAL,1928, p.37). O seu custo foi de 97:200\$000. Sobre o Dr. Joaquim Assumpção, cujo custo foi de aproximadamente 320:000\$000, Augusto Simões Lopes afirmou:

O magestoso prédio, projecto do engenheiro Sylvio Barbedo, com indicações do então director de obras, dr. Ewbank da Câmara, possue 2 pavimentos, é de estylo neomutular e eleva-se no centro de belo jardim, o que dá, certamente, maior realce ás suas linhas architectonicas. Possue o edifício 5 espaçosas salas para aula, 2 gabinetes para a directoria e o medico escolar, 2 roupeiros e todos os serviços sanitários exigíveis em uma casa desta natureza. (RELATÓRIO INTENDENCIAL, 1927, p.80).

Ao comparar as fotografias das escolas rurais com as dos grupos escolares, especialmente o Dr. Joaquim Assumpção, percebe-se que existia uma primazia da zona urbana (local das obras mais visíveis) sobre a zona rural. Para Souza (1996), os grupos escolares foram criados especialmente para atender os núcleos urbanos, revelando a direção de uma política educacional que privilegiava as cidades em detrimento da zona rural. Certamente, deve-se levar em conta que as escolas rurais, individualmente, atendiam a menos alunos do que as escolas urbanas. Contudo, através da observação das fotografias, percebe-se uma grande disparidade nas construções e uma hierarquia (transmitida através das imagens e do "Regulamento da Instrucção"). Desvela-se, então, uma ligação intrínseca entre escola e cidade, muito bem descrita por Faria Filho (1996), quando esse afirma que construir os grupos, considerados espaços ideais para a educação, faz parte da construção da cidade idealizada pela elite republicana. Segundo ele: 
Escola e cidade, ambas criadoras e criaturas: é uma escola que vai se legitimando como uma forma não apenas de educar as crianças e, de transformá-las, mas também de influir nos destinos da cidade. A escola, neste sentido, se cria ao criar a cidade, é uma cidade que se produz nos momentos da escola, e produz a escola como um de seus momentos, (FARIA FILHO, 1996, p.110).

O espaço criado pelo grupo escolar propiciava o distanciamento do mundo doméstico e religioso. A criação de uma nova estrutura escolar evidenciou, simbólica e materialmente, a vinculação da escola com o mundo secular, público e urbano. Esse novo tipo de escola fazia parte de um conjunto maior de melhoramentos urbanos, tornando-se denotativo do progresso de uma localidade. Para Souza (1996), ele era um símbolo de modernização cultural, a morada de um dos mais caros valores urbanos - a cultura escrita. Sendo assim, tanto os fios elétricos que cruzam a fotografia do Grupo Escolar Dr. Joaquim Assumpção quanto a própria escola transformam-se em símbolos de modernidade, de progresso e de desenvolvimento urbano. A educação da cidade era, portanto, privilegiada.

\section{Considerações finais}

Nesse artigo foram analisados diversos pontos, como a localização da imagem nos impressos e a relação com a hierarquia existente entre as diferentes escolas. Percebeu-se que o lugar que a fotografia ocupa não é inocente.

De acordo com Leite, as comparações entre elementos constituintes da imagem (tais como simetrias e assimetrias, ou determinados códigos) sugerem meios de discriminar entre o significativo, o acidental e o redundante nas mensagens. As ligações simbólicas estabelecidas e o estudo das sequências rituais são índices preciosos para mapear e representar o conteúdo latente da fotografia histórica. Dessa forma, não se utilizou apenas do conteúdo da imagem para perceber a sua função social definida, mas de outros elementos que cercavam o con- 
junto de fotografias produzido por Simões Lopes, tais como os textos escritos e as legendas.

Conclui-se que a fotografia de prédios escolares foi uma das formas utilizadas para afirmar a propaganda da imprensa republicana com relação ao governo de Augusto Simões Lopes.

\section{Notas}

\footnotetext{
'Doutoranda em Educação na FaE/UFPel. Pesquisadora do Centro de Estudos e Investigações em História da Educação - CEIHE. E-mail: martiarena.augusta@gmail.com Professor Titular da FaE/UFPel. Pesquisador do Centro de Estudos e Investigações em História da Educação - CEIHE. E-mail: tambara@ufpel.edu.br

Professora da FaE/UFPel. Pesquisadora do Centro de Estudos e Investigações em História da Educação - CEIHE. E-mail: giana@ufpel.edu.br

${ }^{4} \mathrm{O}$ modelo do grupo escolar do "typo" rural foi apresentado no Relatório Intendencial de 1925 .
}

\section{Referências}

ALVES, Nilda. O espaço escolar e suas marcas: o espaço como dimensão material do currículo. Rio de Janeiro: DP\&A, 1998.

BENITO, Agustín Escolano. Tiempos y espacios para la escuela - Ensayos históricos. Editorial Biblioteca Nueva. S.L., Madrid, 2000.

BORGES, Maria Eliza Linhares. História \& fotografia. Belo Horizonte: Autêntica, 2003.

BUFFA, Ester. Arquitetura e educação: organização do espaço e propostas pedagógicas dos grupos escolares paulistas, 1893-1971. São Carlos: Brasília: EdUFSCar, INEP, 2002. p.17-56.

FARIA FILHO, Luciano Mendes de. Dos pardieiros aos palácios: forma e cultura escolares em Belo Horizonte. São Paulo: USP, 1996. KOSSOY, Boris. Fotografia e história. São Paulo: Ática, 1989. 
. Realidades e ficções na trama fotográfica. Cotia, SP: Ateliê Editorial, 1999.

LE GOFF, Jacques. História e memória. Campinas, SP: Editora da UNICAMP, 1992.

LEITE, Mirian Moreira. Retratos de família: leitura de fotografia histórica. São Paulo: Editora da Universidade de São Paulo, 1993. (Texto \& Arte; vol. 9).

. Texto Visual e Texto Verbal. In: FELDMAN-BIANCO, Bela; LEITE, Mirian L. Moreira (orgs.). Desafios da imagem: fotografia, iconografia e vídeo nas ciências sociais. Campinas, SP: Papirus, 1998.

SOUZA, Rosa Fátima. Templos de civilização: um estudo sobre a implantação dos grupos escolares no estado de São Paulo. São Paulo: USP, 1996.

VIÑAO FRAGO, Antonio. Currículo, espaço e subjetividade: a arquitetura como programa. - 2. ed. - Rio de Janeiro: DP\&A, 2001. 


\title{
Photographs of school buildings: the construction of visible workships as government advertisement Simoes Lopes, in the city of Pelotas
}

\begin{abstract}
Between 1924 and 1928, Augusto Simões Lopes was mayor of the Pelotas City, by the "Partido Republicano Rio-Grandense". During his government, a great group of images about education was produced. This group was made to belong to the "Relatórios Intendenciais" (reports presented every year in September) and to be published in the republican press, especially in the "Diario Popular" Newspaper and in the "Almanach de Pelotas". The uses that were given to these pictures were something innovative in the Pelotas City, therefore any mayor before Augusto Simões Lopes produced a group so significant of images related to this topic. The pictures depict, in general, the facade of the school building (rural schools and urban school groups), wich demonstrates a political necessity that, according to Alves, is linked to the executive's attraction for the visible space as instrument that would allow the continuity of a political career. For the realization of this work, we opted for an approach with the theoretical of the New History, especially Jacques Le Goff. Besides, we were used other authors, that had worked with pictures in their investigations, for example Kossoy and Mirian Leite. Therefore, we looked for a base for the realization of the pictures' analysis. We still tried to understand the context of the moment in wich the investigation is developed, through authors that made investigations on the same topic in national and regional ambit.
\end{abstract}

Keywords: Education, Photograph, First Republic

Recebido em: Abril/2009

Aceito em: Junho/2009 
